\author{
Abstracta Iranica \\ Abstracta Iranica Revue bibliographique pour le domaine irano-aryen \\ Volume 34-35-36 | 2017 \\ Comptes rendus des publications de 2011-2013
}

\title{
Kourosh Roustaei, Ahmad Azadi. Discovery of a Parthian Tomb Chamber in Cheram, Kohgiluye, SW Iran
}

\section{Rémy Boucharlat}

\section{(2) OpenEdition}

Journals

Édition électronique

URL : http://journals.openedition.org/abstractairanica/41494

DOI : 10.4000/abstractairanica.41494

ISSN : 1961-960X

Éditeur :

CNRS (UMR 7528 Mondes iraniens et indiens), Éditions de l'IFRI

Référence électronique

Rémy Boucharlat, « Kourosh Roustaei, Ahmad Azadi. Discovery of a Parthian Tomb Chamber in Cheram, Kohgiluye, SW Iran », Abstracta Iranica [En ligne], Volume 34-35-36 | 2017, document 2, mis en ligne le 15 juillet 2016, consulté le 05 octobre 2020. URL : http://journals.openedition.org/abstractairanica/41494 ; DOI : https://doi.org/10.4000/abstractairanica.41494

Ce document a été généré automatiquement le 5 octobre 2020.

Tous droits réservés 


\title{
Kourosh Roustaei, Ahmad Azadi. Discovery of a Parthian Tomb Chamber in Cheram, Kohgiluye, SW Iran
}

\author{
Rémy Boucharlat
}

\section{RÉFÉRENCE}

Kourosh Roustaei, Ahmad Azadi. « Discovery of a Parthian Tomb Chamber in Cheram, Kohgiluye, SW Iran ». IA, 46, 2011, p. 193-206.

1 Les témoins archéologiques de l'époque parthe sont rares et sont souvent des tombes. Celle qui a été découverte fortuitement près de Dehdašt dans le Zagros centralméridional en apporte une nouvelle illustration. C'est une belle construction souterraine en pierre de 3,80 $\mathrm{m}$ de long, 1,30 $\mathrm{m}$ de large et $1 \mathrm{~m}$ de hauteur, couverte par de grandes dalles. A côté de quelques objets en bronze (vases, miroir) et une épée en fer, difficiles à dater, le matériel céramique, gourde sans glaçure, gourde et pots à glaçure bleue ou bleu-vert indique une date entre le $1^{\mathrm{er}}$ s. avant et le $\mathrm{II}^{\mathrm{e}} \mathrm{s}$. après J.-C. C'est la période préislamique la mieux connue dans la région depuis les sites Suse et Dostova dans la plaine jusqu'à Masjed Soleymān, sans oublier les nombreux bas-reliefs.

\section{AUTEURS}

RÉMY BOUCHARLAT

CNRS, Lyon 